\title{
Proton Pump Inhibitor-induced Hypersensitivity Reaction: A Case Report
}

\author{
Anjan Adhikari ${ }^{1}$, Rania Indu ${ }^{1}$, Moumita Ray ${ }^{1}$, Sangita Bhattacharya ${ }^{1}$, Rahul Biswas ${ }^{1}$, Anup Kumar Das ${ }^{1}$ \\ 'Department of Pharmacology, R. G. Kar Medical College, Khudiram Bose Sarani, Kolkata-700004, West Bengal, INDIA.
}

\begin{abstract}
Introduction: Drug induced allergy or hypersensitivity reaction is of great clinical significance in therapeutics. Various factors may contribute like age, genetic composition, disease of the patients and the types of drugs used. Such reactions increases the patient's suffering and lowers the therapeutic efficacy of any drug. Therefore, it is essential to collect data and investigate important drug reactions for safe therapy. Presentation of Case: A 27-years old female patient, with a history of drug allergy to ranitidine, experienced severe anaphylactic shock immediately after cesarean delivery. Post-operative medications include Ceftriaxone, Metronidazole, Tramadol, Metoclopramide and Pantoprazole. With intravenous injections of Adrenaline, Hydrocortisone, Dexamethasone, Atropine, Promethazine and intubation, she slowly recovered after three days and was discharged. Conclusion: Past history of the patient suggested a rare case of drug allergy to ranitidine. Therefore, instead of ranitidine, pantoprazole was used for this patient. Clinicians suspected this anaphylactic reaction may be induced by drug. However, the drug responsible for this reaction was not detected
\end{abstract}

clearly but Pantoprazole may be a possibility. Though allergy due to $\mathrm{H}_{2}$ receptor antagonists and proton-pump inhibitors are rare but may cause fatal consequences. Thus proper investigation of this case may help in designing the treatment schedule in an effective way, in future.

Key words: Anaphylactic shock, Drug Hypersensitivity, H2 Receptor Antagonist, Pantoprazole, Proton-pump Inhibitors, Ranitidine.

\section{Correspondence:}

Dr. Anjan Adhikari,

Department of Pharmacology, R. G. Kar Medical College, 1, Khudiram Bose Sarani, Kolkata-700004, West Bengal, INDIA.

Mob: 09831012503

E-mail: dradhikarianjankolkata@gmail.com

DOI: 10.5530/jyp.2017.9.28

\section{INTRODUCTION}

Drug-induced hypersensitivity is an immune-mediated reaction in response to a drug. The common manifestations include itching, rashes and anaphylaxis. Anaphylaxis is a severe, potentially, life-threatening allergic reactions. Drug hypersensitivity reactions are commonly encountered in clinical practice, approximately $15 \%$ of the adverse drug reactions were observed in drug therapy. ${ }^{1}$ The drug acts as an antigen and induces the development of various chemical mediators and antibodies that finally gives rise to an immense immunogenic reaction causing hypersensitivity. This response varies from person to person and depend on the type and dose of the drug, the age and genetic composition of the patient and the diseases. ${ }^{1}$ Thus, identification of these hypersensitive reactions, the causative drug, causality relationship between the drug and the reaction, are essential to optimize the therapeutic safety. Present case report deals with anaphylactic shock experienced by a patient, with a history of drug allergy to Ranitidine, immediately after cesarean delivery.

\section{CASE REPORT}

A 27-years old female patient was admitted at R.G. Kar Medical College, Kolkata, West Bengal state in India on July 2015 for cesarean delivery. Previous history of the patient reported allergy to 'Ranitidine'. Through LUCS (Lower Uterine Cesarean Section) baby was delivered with vertex with the help of forceps. Placenta was delivered by Controlled Cord Traction (CCT). Uterus was repaired in two layers. Homeostasis was secured. For post-operative treatment, she was prescribed Ceftriaxone (1gm, i.v), Metronidazole (100, i.v), Tramadol (1 amp, i.m), Metoclopramide and Pantoprazole (i.v). Pantoprazole was prescribed as the patient was reactive to Ranitidine, $\mathrm{H}_{2}$ receptor antagonists.
But immediately after post-operative medication, patient suddenly started suffering from severe bronchospam, cyanosis, edematous face and skin (Figure 1). She lost her consciousness and her extremities were cold and clammy. Her heart rate was $160 / \mathrm{min}$, blood pressure $80 / 40 \mathrm{~mm}$ of $\mathrm{Hg}$, Oxygen saturation was $80 \%$. A probable diagnosis predicted it as a case of 'drug-induced anaphylactic shock'. Immediate treatment started with mask ventilation, followed by intubation with $7 \mathrm{~mm}$ ID (internal diameter), endotracheal tube (ETT). Intravenous injections of Adrenaline, Hydrocortisone (200 ug), Dexamethasone (8 mg), Atropine (1 amp), Promethazine ( $1 \mathrm{amp}$ ) were administered. She was under continuous monitoring. She regained her consciousness after about 24 hours. Her heart rate was 95/min, blood pressure 122/72 mm of $\mathrm{Hg}$, Oxygen saturation was $100 \%$. She was kept under observation for three more days before discharge.

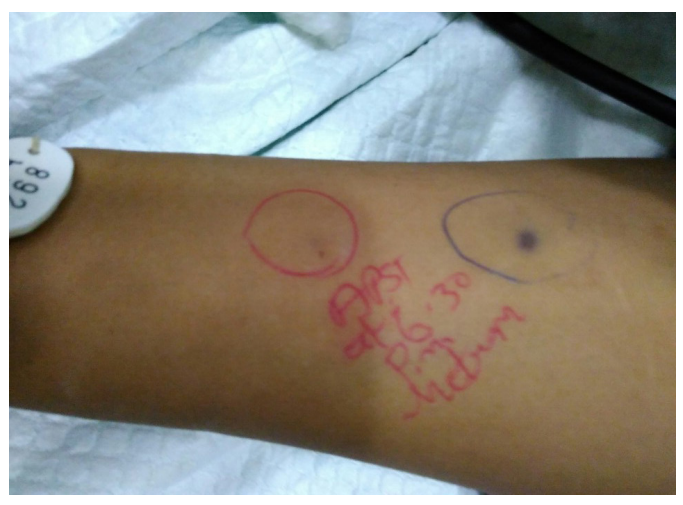

Figure 1: Edematous skin of the patient.

This is an open access article distributed under the terms of the Creative Commons Attribution-NonCommercial-ShareAlike 4.0 License, which allows others to remix, tweak, and build upon the work non-commercially, as long as the author is credited and the new creations are licensed under the identical terms. 
Drugs prescribed at the time of discharge include Meropenem (1gm), Amikacin (1 gm), Metronidazole (500), Hydrocortisone (50).

\section{DISCUSSION}

Treatment of gastric acid related disorders revolutionized after the discovery of $\mathrm{H}_{2}$ receptor antagonists and proton-pump inhibitors. These are usually well-tolerated with minimum adverse effects. Uppsala Monitoring Centre database reported the adverse effects of both $\mathrm{H}_{2}$ receptor antagonists and proton-pump inhibitors accounts for only $0.2-0.7 \%$ of all the incidences of anaphylaxis. ${ }^{2}$ Ranitidine is a histamine $\mathrm{H}_{2}$-receptor antagonist that reduces stomach acid production and is used to treat peptic ulcer and gastroesophageal reflux diseases. It is a well-tolerated drug with very few reports on drug hypersensitivity. ${ }^{3}$ Anaphylaxis, a clinical symptom, is often life threatening and involves respiratory and cardiovascular problems. On encounter of an antigen, pro-inflammatory mediators are released from the mast cells and basophils that lead to severe allergic conditions. ${ }^{4}$ However, recently few cases on anaphylactic reaction due to ranitidine have been reported. Allergic reaction was observed in a 9-month old girl in Spain and 18-year old male in Italy and was suspected to be due to ranitidine. ${ }^{5,6}$ Intravenous injection with ranitidine in an 47-year-old woman in Italy and a 36-year-old man from Tunisia, developed anaphylactic reaction. ${ }^{7,8}$ Severe anaphylactic reaction was also reported in India, in a 25-year old female, who was injected with ranitidine during cesarean section against spinal anesthesia. ${ }^{9}$ Present case report also documents a history of ranitidine allergy by the patient. Therefore, Pantoprazole was prescribed to the patient as post-operative medication. Pantoprazole is a proton-pump inhibitor used to inhibit gastric acid secretion. Few case reports suggest pantoprazole may lead to anaphylactic shock..$^{10}$ A 50 -year old male in China also experienced anaphylactic shock due to intravenous injection of pantoprazole during general anesthesia. ${ }^{11}$ A unique case report also suggested a 57-year old male in Britain, suffering from gastroesophageal reflux, was unresponsive to ranitidine. Therefore he was prescribed pantoprazole that developed acute interstitial nephritis. ${ }^{12}$

The other drugs that were prescribed to the patient in the present study include Ceftriaxone, a third-generation antibiotic, known to have various adverse effects. A study in this hospital conducted on 2014 showed 33.4\% of the ADRs are caused by this antibiotic. ${ }^{13}$ A 7 -year old boy in Pondicherry in India was found to suffer from hypersensitivity reaction due to Ceftriaxone. ${ }^{14}$ Metronidazole, used in infection, is usually well-tolerated. However, few case reports were documented that report hypersensitivity due to Metronidazole, as was observed in a 65-years old woman in Ohio. ${ }^{15}$ A rare case of hypersensitivity to Metoclopramide (Reglan) was observed in a 30-year-old woman in Poland. ${ }^{16}$ In the present study, patient did not have any problem with use of other drugs, except Ranitidine. So, possibility of hypersensitivity with Pantoprazole may be one of the cause, though need investigation.

Thus, in the present case study, it is necessary to investigate for a probable cause for the development of anaphylactic shock. It is essential to find out which drug is responsible for the anaphylactic shock and if there is any correlation between allergy of the patient to ranitidine and development of anaphylactic shock due to pantoprazole. The other drugs used may also possess causality relation to the hypersensitive condition. This type of idiosyncratic behavior is important for the physicians to predict the adverse reaction of a particular drug and accordingly prescribe the therapeutic regimen for the patient.

\section{CONCLUSION}

Ranitidine, pantoprazole are commonly used drugs for the treatment of peptic ulcer and gastroesophageal reflux disorders. But allergies due to these drugs were observed rarely. However, this present case study of post-operative anaphylactic shock in a 27 -year old female patient with history of allergy to ranitidine needs investigation for scientific exploration. Anaphylactic reaction was managed with medication and intubation. However, knowledge of these types of rare events should be disseminated to create awareness among the scientists, researchers and physicians. This ultimately ensures the approach for safe therapy.

\section{ABBREVIATIONS USED}

ADR: Adverse Drug Reactions; Amp: ampule; CCT: Controlled Cord Traction; ETT: Endotracheal tube; gm: Gram; Hg: Mercury; ID: Internal Diameter; IM: Intramuscular; IV: Intravenous; LUCS: Lower Uterine Cesarean Section; mg: Milligram; min: Minute; mm: Millimeter; ug: Microgram.

\section{REFERENCES}

1. Walker Al, Werfel S, Kick G, Przybilla B. Repeated anaphylactic responses induced by oral challenge with ranitidine. Acta Derm Venereol. 2010;90(2):189. http://dx.doi.org/10.2340/00015555-0773; PMid:20169307.

2. Song WJ, Kim MH, Lee SM, Kwon YE, Kim SH, Cho SH, et al. Two Cases of H2-Receptor Antagonist Hypersensitivity and Cross-Reactivity. Allergy, Asthma and Immunology Research. 2011;3(2):128-31. http://dx.doi.org/10.4168/ aair.2011.3.2.128; PMid:21461253 PMCid:PMC3062792.

3. Frampton JE, McTavish D. Ranitidine. A pharmcoeconomic evaluation of its use in acid related disorders. Pharmcoeconomics. 1994;6:57-89. http://dx.doi. org/10.2165/00019053-199406010-00007.

4. Hepner DL, Castells MC. Anaphylaxis during the perioperative period. Anesth Analg. 2003;97(5):1381-95. http://dx.doi.org/10.1213/01.ANE.0000082993.84883. 7D; PMid:14570656.

5. Cuevas-Castillejos H, Cuevas-Castillejos JE, García-Murray O, LarenasLinnemann D. Allergy to ranitidine: one case report and literature review. Rev Alerg Mex. 2013;60(1):41-8. PMid:24008069.

6. Antonicelli L, Stagnozzi G, Massaccesi C, Manfredi M, Valentini M, Campi P. Intraoperative anaphylaxis: a case report of allergy to ranitidine. Eur Ann Allergy Clin Immunol. 2012;44(6):253-5. PMid:23441444.

7. Foti C, Cassano N, Panebianco R, Calogiuri GF, Vena GA. Hypersensitivity reaction to ranitidine: description of a case and review of the literature. Immunopharmacol Immunotoxicol. 2009;31(3):414-6. http://dx.doi.org/10.1080/ $08923970902739078 ;$ PMid:19694603.

8. Aouam K, Bouida W, Ben Fredj N, Chaabane A, Boubaker H, Boukef R, Boughattas NA, Nouira S. Severe ranitidine-induced anaphylaxis: a case report and literature review. J Clin Pharm Ther. 2012;37(4):494-6. http://dx.doi.org/10.1111/j.13652710.2011.01320.x; PMid:22059646.

9. Sripriya R, Kumar VRH, Prabhu R, Ravishankar M. Intraoperative anaphylaxis to ranitidine during cesarean section. Journal of Natural Science, Biology, and Medicine. 2013;4(1):257-9. http://dx.doi.org/10.4103/0976-9668.107321; PMid:23633878 PMCid:PMC3633294

10. Kollmeier AP, Eddleston J, Zuraw BL, Christiansen SC. Recurrent idiopathic anaphylaxis linked to pantoprazole. Journal of Allergy and Clinical Immunology. 2004;113(2): S310 http://dx.doi.org/10.1016/j.jaci.2004.01.612.

11. Lai HC, Hsu SW, Lu CH, Ma H, Cherng CH, Hung NK, Wu CT. Anaphylaxis to pantoprazole during general anesthesia. J Anesth. 2011;25(4):606-8. http:// dx.doi.org/10.1007/s00540-011-1148-x; PMid:21626263.

12. Ricketson J, Kimel G, Spence J, Weir R. Acute allergic interstitial nephritis after use of pantoprazole. CMAJ: Canadian Medical Association Journal. 2009;180(5):535-8. http://dx.doi.org/10.1503/cmaj.080456; PMid:19255077 PMCid:PMC2645468.

13. Adhikari A, Saha A, Ray M, Bhowal T, Ganguly A, Das AK. Ceftriaxone related adverse drug reactions in children in a tertiary care hospital, Kolkata, West Bengal, India. Exploratory Animal Med Res. 2014;4:444-7.

14. Arulraj R, Venkatesh $C$, Chhavi N, Soundararajan P. Hypersensitivity due to ceftriaxone mimicking measles in a child. Indian Journal of Pharmacology. 2013;45(5):528-9. http://dx.doi.org/10.4103/0253-7613.117756; PMid:24130394 PMCid:PMC3793530

15. Gendelman SR, Pien LC, Gutta RC, Abouhassan SR. Modified oral metronidazole desensitization protocol. Allergy and Rhinology. 2014;5(2):e66-9. http:// dx.doi.org/10.2500/ar.2014.5.0080; PMid:24612959 PMCid:PMC4124580.

16. Pietrzko P, Zakrzewski A, Matuszewski T, Kruszewski J. Angioneurotic edema: a rare case of hypersensitivity to metoclopramide. Advances in Dermatology and Allergology/Post冈py Dermatologii I Alergologii. 2013;30(2):117-8. http://dx.doi. org/10.5114/pdia.2013.34163; PMid:24278059 PMCid:PMC3834686. 
Article History: Submission Date : 22-09-16; Accepted Date : 01-10-16.

Cite this article: Adhikari A, Indu R, Ray M, Bhattacharya S, Biswas R, Das AK. Proton Pump Inhibitor-induced Hypersensitivity Reaction: A Case Report. J

Young Pharm. 2017;9(1):137-9. 